\title{
Mating skew in Barbary macaque males: the role of female mating synchrony, female behavior, and male-male coalitions
}

\author{
Annie Bissonnette • Nicole Bischofberger • \\ Carel $P$ van Schaik
}

Received: 18 March 2010 /Revised: 6 July 2010 /Accepted: 8 July 2010 / Published online: 23 July 2010

(C) Springer-Verlag 2010

\begin{abstract}
A fundamental question of sexual selection theory concerns the causes and consequences of reproductive skew among males. The priority of access (PoA) model (Altmann, Ann NY Acad Sci 102:338-435, 1962) has been the most influential framework in primates living in permanent, mixed-sex groups, but to date it has only been tested with the appropriate data on female synchrony in a handful of species. In this paper, we used mating data from one large semi-free ranging group of Barbary macaques: (1) to provide the first test of the priority-ofaccess model in this species, using mating data from 11 sexually active females (including six females that were implanted with a hormonal contraceptive but who showed levels of sexual activity comparable to those of naturally cycling females) and (2) to determine the proximate mechanism(s) underlying male mating skew. Our results show that the fit of the observed distribution of matings with sexually attractive females to predictions of the PoA model was poor, with lower-ranking males mating more than expected. While our work confirms that female mating synchrony sets an upper limit to monopolization by high-ranking individuals, other factors are also important. Coalitionary activity was the main tactic used by males to lower mating skew in the study group. Coalitions were
\end{abstract}

Communicated by A. Widdig

A. Bissonnette · N. Bischofberger · C. P. van Schaik

Anthropological Institute and Museum, University of Zurich,

Zurich, Switzerland

A. Bissonnette $(\bowtie)$

Courant Research Center Evolution of Social Behavior,

University of Göttingen,

Göttingen, Germany

e-mail: a.bissonnette@aim.uzh.ch expressed in a strongly age-related fashion and allowed subordinate, post-prime males to increase their mating success by targeting more dominant, prime males. Conversely, females, while mating promiscuously with several males during a given mating cycle, were more likely to initiate their consortships with prime males, thus reducing the overall effectiveness of coalitions. We conclude that high-ranking Barbary macaque males have a limited ability to monopolize mating access, leading to a modest mating skew among them.

Keywords Reproductive skew - Priority of access model · Male-male coalitions · Mate choice - Promiscuous mating · Affenberg Salem $\cdot$ Hormonal implants

\section{Introduction}

The causes and consequences of reproductive skew, i.e. the extent to which particular individuals monopolize breeding, have received much theoretical and empirical attention in the last few decades (reviewed in Johnstone 2000). The reproductive skew theory has been divided in two broad categories (Clutton-Brock 1998; Johnstone 2000; Kutsukake and Nunn 2006). Transactional models propose that reproduction is controlled by the dominant individual, who allows the subordinates to reproduce to a certain extent as a staying incentive (Keller and Reeve 1994; Clutton-Brock 1998; Johnstone 2000), whereas limited control or compromise models suggest that the dominant individual is unable to completely prevent the reproduction by subordinates (Cant 1998; Clutton-Brock 1998; Reeve et al. 1998). Empirical studies have provided mixed results for variants of both models in species of social insects, cooperatively breeding birds, and mammals (reviewed in Magrath and Heinsohn 
2000; Clutton-Brock et al. 2001; Reeve and Keller 2001; Kutsukake and Nunn 2008).

In primates, the priority of access model (i.e. PoA model; Altmann 1962), which can be viewed as a special case of the more general limited-control models of reproductive skew (Kutsukake and Nunn 2009), has been commonly used to set the basic expectation of skew among males. This model states that the degree to which the dominant male monopolizes matings within a group is affected by the number of females that mate simultaneously. When two females are in estrous simultaneously, the alpha male is unable to effectively monopolize mating access to both of them effectively, thus allowing the beta male to mate, and so on down the male hierarchy as the number of estrous females increases. Consequently, variability in mating and thus reproductive success should be a function of male dominance rank and the number of females that are simultaneously in estrus. An indirect way to test the PoA model is to look for the presence of a relationship between male dominance rank and some estimate of mating or reproductive success.

Many studies exist on the presence of the relationships between male rank and both mating (e.g. Cowlishaw and Dunbar 1991; Bulger 1993; Ellis 1995; Alberts et al. 2003; Kutsukake and Nunn 2006) and paternity success (e.g. van Noordwijk and van Schaik 2004; Widdig et al. 2004; Charpentier et al. 2005; Engelhardt et al. 2006; RodriguezLlanes et al. 2009) in a wide range of species, but the strength of this relationship is quite variable. Even though the presence of this relationship is predicted by the PoA model (except in the extreme case where all females are receptive simultaneously), this evidence is not sufficient to support the model, because higher-ranking males may mate and reproduce more than lower-ranking males, but still less than would be expected based on female mating synchrony alone (i.e. the slope of the regression curve of success on rank is shallower than expected based on the PoA model, e.g. Chapais 1983b; Alberts et al. 2003).

To date, the predictions of the PoA model have only been tested with the appropriate data on female synchrony for a handful of species (savanna baboons: Hausfater 1975; Altmann et al. 1996; Alberts et al. 2003; chacma baboons: Weingrill et al. 2003; rhesus macaques: Chapais 1983b; Japanese macaques: Hayakawa 2007; mandrills: Setchell et al. 2005; chimpanzees: Boesch et al. 2006; Wroblewski et al. 2009). These studies have generally shown that the upper limit to alpha male monopoly is set by the degree of female synchrony, in line with the PoA model. On the other hand, the fit with the predictions of the PoA model was often imperfect, suggesting that in addition to female synchrony other factors can limit monopoly by dominant individuals, such as female mate choice for middle and lower rankers (e.g. Chapais 1983a;
Hayakawa 2007; Pereira and Weiss 1991; Soltis et al. 2001; Stumpf and Boesch 2005; Stumpf and Boesch 2006) and male alternative mating tactics, including friendships with females, surreptitious matings, and female coercion (reviewed in Smuts 1987; Setchell 2008), and coalitionary activity. So far, the best documented cases of reproductive coalitions have been reported in savanna baboon males (Packer 1977; Bercovitch 1988; Noë and Sluijter 1990), and anecdotal reports exist in one macaque species (Macaca tonkeana, Thierry 2007). This type of coalition has been labeled allup leveling, because they make the distribution of matings or paternities among male ranks more egalitarian (Pandit and van Schaik 2003). The degree to which these factors are important in producing deviations from the PoA model is probably contingent upon the demography and social system of the species or population (e.g. Alberts et al. 2003; Setchell et al. 2005). Thus, tests of the PoA model in a variety of species in different settings are needed in order to understand the proximate mechanisms underlying mating and reproductive skew in primates.

Barbary macaques represent an interesting study system to test the applicability of the PoA model. They live in multi-male multi-female groups of up to 88 individuals in natural populations and show a distinct mating season restricted to autumn and winter in natural and foodenhanced populations (reviewed in Fooden 2007). Several females in the same group are sexually active concurrently (Kuester and Paul 1984; Paul 1989; Small 1990; Kuester and Paul 1992; Brauch et al. 2008). Published field studies of reproductive success in Barbary macaques suggests that a low to medium skew (based on the proportion of mating/ paternities going to the top-ranking male, cf. van Noordwijk and van Schaik 2004) is a constant characteristic of this species (Table 1), but it remains unclear whether female mating synchrony is the main factor responsible for this outcome.

In addition to female mating synchrony, two main behavioral mechanisms exist in Barbary macaques that may contribute to decrease mating skew among males, namely, female mating behavior and male-male coalitions (see references below). Each mechanism has been described to a certain extent in independent studies (Table 1), but this is the first study that attempts to evaluate whether these two factors may cause deviations from the expectation based on the PoA model. Additional mechanisms such as surreptitious matings and harassment of consorting males have been described in subadult males of this species (Kuester and Paul 1989) but, because this age class was absent from the study group, we will henceforth ignore them. First, it is a well-established fact that female Barbary macaques play an active role in initiating and terminating their consortships, mate with multiple males during both their non- 
Table 1 Results of field studies of mating/reproductive success in Barbary macaques

\begin{tabular}{|c|c|c|c|c|c|c|c|c|}
\hline Study & $\begin{array}{l}\text { Living } \\
\text { conditions }\end{array}$ & $\begin{array}{l}\text { Number } \\
\text { of adult } \\
\text { males }^{\mathrm{a}}\end{array}$ & $\begin{array}{l}\text { Estimate of mating/ } \\
\text { reproductive success }\end{array}$ & $\begin{array}{l}\text { Proportion of } \\
\text { mating or infants } \\
\text { sired by alpha }{ }^{b}\end{array}$ & $\begin{array}{l}\text { Correlation } \\
\text { rank/ } \\
\text { measure of } \\
\text { success }\end{array}$ & $\begin{array}{l}\text { Male-- } \\
\text { male } \\
\text { coalitions }\end{array}$ & $\begin{array}{l}\text { Female } \\
\text { behavior }\end{array}$ & $\begin{array}{l}\text { Female cycle } \\
\text { synchrony }\end{array}$ \\
\hline $\begin{array}{l}\text { Taub } \\
(1980)\end{array}$ & Wild & 7 & $\begin{array}{l}\text { Ejaculatory copulations } \\
\text { during maximum sexual } \\
\text { swelling of females }\end{array}$ & 0.24 & $\begin{array}{l}\text { High }>\text { low } \\
\text { rankers }\end{array}$ & Rare & Promiscuous & $?$ \\
\hline $\begin{array}{l}\text { Kümmerli } \\
\text { and } \\
\text { Martin } \\
(2005)\end{array}$ & Provisioned & $11-12$ & Genetic paternity markers & $\sim 0.25$ & No & $?$ & $?$ & $?$ \\
\hline $\begin{array}{l}\text { Modolo } \\
\text { and } \\
\text { Martin } \\
(2008)\end{array}$ & Provisioned & $5-12$ & Genetic paternity markers & $0.06[0-0.11]$ & No & $?$ & $?$ & $?$ \\
\hline $\begin{array}{l}\text { Brauch et } \\
\text { al. (2008) }\end{array}$ & Provisioned & $4-6^{\mathrm{a}}$ & $\begin{array}{l}\text { Ejaculatory copulations } \\
\text { during the fertile period } \\
\text { and genetic paternity } \\
\text { markers }\end{array}$ & $?$ & $\begin{array}{l}\text { High }>\text { low } \\
\text { rankers }\end{array}$ & $?$ & $\begin{array}{l}\text { Promiscuous } \\
\text { and choice for } \\
\text { higher- } \\
\text { rankers }\end{array}$ & $\begin{array}{l}30 \% \text { overlap } \\
\text { in fertile days }\end{array}$ \\
\hline $\begin{array}{l}\text { Paul } \\
\text { (1989), } \\
\text { Paul et al. } \\
(1993)\end{array}$ & $\begin{array}{l}\text { Semi-free } \\
\text { ranging }\end{array}$ & $5-9$ & $\begin{array}{l}\text { Ejaculatory copulations } \\
\text { during the conceptional } \\
\text { week }\end{array}$ & $0.29[0.20-0.38]$ & $\begin{array}{l}\text { Yes in one of } \\
\text { two mating } \\
\text { seasons }\end{array}$ & $?$ & $?$ & $\begin{array}{l}\text { Mean, 2.9-3.1 } \\
\text { fertile } \\
\text { females/day } \\
\text { in Nov. }\end{array}$ \\
\hline $\begin{array}{l}\text { Kuester } \\
\text { and Paul } \\
(1996)\end{array}$ & $\begin{array}{l}\text { Semi-free } \\
\text { ranging }\end{array}$ & $16-33^{\mathrm{a}}$ & Genetic paternity markers & $\sim 0.16$ & $\mathrm{No}^{\mathrm{c}}$ & Yes & $?$ & $?$ \\
\hline $\begin{array}{l}\text { Kuester } \\
\text { and Paul } \\
(1992)\end{array}$ & $\begin{array}{l}\text { Semi-free } \\
\text { ranging }\end{array}$ & 25 & $\begin{array}{l}\text { Ejaculatory copulations } \\
\text { during the conceptional } \\
\text { week }\end{array}$ & $\leq 0.13$ & No? ${ }^{d}$ & Yes & Promiscuous & $\begin{array}{l}4-21 \text { females } \\
\text { sexually } \\
\text { active } \\
\text { (mean, } \sim 13 \text { ) }\end{array}$ \\
\hline $\begin{array}{l}\text { Small } \\
(1990)\end{array}$ & $\begin{array}{l}\text { Semi-free } \\
\text { ranging }\end{array}$ & 11 & $\begin{array}{l}\text { Copulations during } \\
\text { maximum sexual swelling } \\
\text { of females }\end{array}$ & $?$ & $?$ & $?$ & Promiscuous & $\begin{array}{l}58 \% \text { infants } \\
\text { conceived in } \\
1 \text { month }\end{array}$ \\
\hline $\begin{array}{l}\text { Witt et al. } \\
(1981)\end{array}$ & Captive & $1-2$ & Genetic paternity markers & $0.69[0.46-100]$ & $\begin{array}{l}\text { (only one to } \\
\text { two adult } \\
\text { males) }\end{array}$ & Yes & $?$ & $?$ \\
\hline
\end{tabular}

${ }^{a}$ Adult males are $\geq 7$ years old except for the following studies: Brauch et al. (2008), $\geq 5$ years old; Paul et al. (1993) and Kuester and Paul (1996), mature males $\geq 4.5$ years old

${ }^{b}$ The mean proportion per group/year is given for studies with more than one breeding season and the range is shown in brackets when available

${ }^{\mathrm{c}}$ Correlation is significant if the subadult males (sexually mature but not yet full adult body size) are included

${ }^{\mathrm{d}}$ The low number of agonistic interactions did not allow the construction of a dominance hierarchy

fertile and fertile periods, and are generally cooperative with all potential mates (Taub 1980; Small 1990; Kuester and Paul 1992; Paul et al. 1993; Menard et al. 2001; Brauch et al. 2008). Although many authors concluded that a lack of female choice or partner preference is characteristic of this species (Taub 1980; Small 1990; Kuester and Paul 1992), Brauch et al. (2008) recently provided evidence of female mate choice for higher rankers during fertile periods. The reason for this variation across studies remains unclear.

Second, the role of male coalitions on mating skew in Barbary macaques is not well understood. Three studies reported that Barbary macaque males form coalitions in the context of mating competition, whereas in another study it was mentioned that coalitions were rarely observed (Table 1). For example, Witt et al. (1981) reported that "the beta and the gamma male together often managed to exclude the alpha male from contact with estrous females" (p. 205), suggesting that Barbary macaque males may sometimes use baboon-like coalitions (e.g. Packer 1977; Bercovitch 1988; Noë and Sluijter 1990) to decrease dominant males' monopoly. In contrast, Kuester and Paul (1992) reported that coalitions were not used by males to usurp females from dominant rivals but apparently as a way for postprime males to peripheralize younger adult competitors during the mating season.

In this study, we investigate the proximate mechanisms underlying male mating skew in a semi-free-ranging group of Barbary macaques with a particularly large number of post-prime males. Using mating data from one mating season, we addressed the following three questions: (1) To 
what extent can the PoA model account for the distribution of matings among male ranks in the study group? (2) Does coalition formation over access to females represent a major alternative mating tactic allowing lower-ranking males to decrease skew? (3) Does female mating behavior contribute to increasing or decreasing mating skew among males?

For management purposes, the majority of the adult females in the study group had been implanted with a hormonal contraceptive before the start of the study. The effect of this hormonal implant on female sexual behavior was variable in the study group, with some females displaying very low levels of sexual activity during the mating season while others showed levels that were comparable to those observed in naturally cycling females (see details in the "Methods" section). To deal with this shortcoming, we carefully selected the females (implanted and non-implanted) to be included in the calculations of the PoA model based on a quantitative assessment of male interest in these females. We considered that the overlap of mating periods of attractive females should determine the degree to which dominant males can actually control mating access within groups and assumed that an implanted female that was mated and consorted by males was perceived as a sexual resource and thus worth competing for. No effort was made at estimating the siring success of males.

\section{Methods}

Study site and study group

The study group inhabited a forested enclosure of 14.5-ha at the Affenberg Salem, Germany (for a history of the colony, see de Turckheim and Merz 1984). Animals were fed once daily with fruits, vegetables, and grains distributed in different areas within the park. The monkeys also fed extensively on natural vegetation, including leaves, herbs, grasses, and bark. Water was available ad libitum. From March to November, tourists were allowed into the enclosure but were restricted to a path.

The study group $(\mathrm{H})$ was composed of 57 individuals, including 27 adult females ( $>5$ years old), 24 adult males (aged between 7 and 25 years old) and six juveniles (Table 2; age was known from birth records). Adult males were classified in two age categories: prime males (i.e. young adults aged between 7 and 12 years) and post-prime males (i.e. middle-aged and old adults aged $>12$ years; $c$. de Turckheim and Merz 1984). Prime males in the study group were "athletic" and had intact, fully erupted canines, in contrast to post-prime males who generally had a less muscular build and showed worn or broken canines. No subadult males were present at the time of the study. All adult animals were recognized individually and habituated to the observers.

Sampling method

Observational data were collected 5 days a week from dawn to dusk during the mating season 2006/2007 (from the end of August until mid-February). A total $373 \mathrm{~h}$ of female focal data (Altmann 1974) were collected by N.B., and $279 \mathrm{~h}$ of male focal data were collected by A.B. During focal follows, all occurrences of sexual behavior (present, inspect, mount, copulations with or without ejaculatory pause, copulation call, estrous call) were noted, as well as the identity of the male partner and a detailed description of the context and locality of changeovers in consortships (see definition below). Moreover, proximity scans were conducted every $5 \mathrm{~min}$ and the activity of the focal individual (grooming, resting, locomotion, foraging) was noted as well as the identity of all adult animals in body contact or grooming with the focal individual and of all adults present within 2,10 , and $30 \mathrm{~m}$. In addition, ad libitum sampling (Altmann 1974) was done by both observers throughout the day, whereby detailed information on sexual activities and agonistic interactions among adult animals were recorded. The percentage of agreement (cf. Martin and Bateson 2000) for focal sampling between A.B. and N.B. was tested in four focal sessions of $15 \mathrm{~min}$ and reached at least $80 \%$ for the behaviors considered in this study.

Focal females were selected based on three criteria relating to female attractiveness: (1) the occurrence of sexual behavior (see above), (2) the presence of males in proximity to the female, and (3) a qualitative assessment of the swelling change. These criteria were evaluated daily, several times per day, by two to three observers. Female follows were then conducted as long as males showed interest in them and on one additional day following the "attractiveness breakdown" (cf. Chapais 1983b; Kuester and Paul 1984). Observation time was equally divided when more than one female was attractive and balanced between morning and afternoon sessions. Depending on the number of attractive females, female focal follows could last from 1 to $4 \mathrm{~h}$ (median, $1 \mathrm{~h}$ ). The vast majority of the data used in the following analyses were obtained from female focal follows.

\section{Hormonal implants}

For management purposes, the majority of the adult females $(n=20)$ had been implanted with a hormonal contraceptive (Norplant ${ }^{\circledR}$, active ingredient-levonogestrel) 1 month to 10 years before the start of the current study (Table 2). In humans, levonogestrel implants prevent pregnancy nearly perfectly for 3 to 5 years (Glasier 2002; Sivin et al. 1997, 
Table 2 Adult animals in the study group H (Affenberg Salem) during the mating season 2006/2007

\begin{tabular}{|c|c|c|c|c|c|c|c|c|c|}
\hline Female ID ${ }^{\mathrm{a}}$ & Age & Rank class & Parity & Implanted since (years) & Male ID & $\operatorname{Rank}^{\mathrm{b}}$ & Age & Age class ${ }^{\mathrm{c}}$ & Natal status ${ }^{\mathrm{d}}$ \\
\hline $\mathrm{Col}$ & 15 & Alpha & M & 4 & Yak & 1 & 14 & Post & $\mathrm{N}$ \\
\hline M2d* & 7 & Beta & $\mathrm{P}$ & 2 & Lud & 2 & 12 & Prime & I \\
\hline Hub & 5 & High & $\mathrm{P}$ & 1 & Ron & 3 & 11 & Prime & I \\
\hline Mum* & 6 & High & $\mathrm{M}$ & 0.08 & Joh & 4 & 7 & Prime & $\mathrm{N}$ \\
\hline Sla & 8 & High & $\mathrm{P}$ & 2 & Pun & 5 & 16 & Post & $\mathrm{N}$ \\
\hline Ali & 10 & High & $\mathrm{P}$ & 2 & Fli & 6 & 9 & Prime & I \\
\hline Jan & 18 & High & $\mathrm{M}$ & 5 & War & 7 & 10 & Prime & I \\
\hline Dir* & 21 & High & $\mathrm{P}$ & 2 & Blo & 8 & 15 & Post & $\mathrm{N}$ \\
\hline Bea & 22 & High & $\mathrm{P}$ & 5 & Hul & 9 & 20 & Post & I \\
\hline Tri* & 6 & Mid & $\mathrm{P}$ & 2 & Leo & 10 & 10 & Prime & I \\
\hline Lol* & 12 & Mid & $\mathrm{P}$ & - & Eyb & 11 & 25 & Post & $\mathrm{N}$ \\
\hline Mad* & 17 & Mid & $\mathrm{N}$ & - & Fro & 12 & 19 & Post & I \\
\hline Man & 19 & Mid & $\mathrm{N}$ & 5 & Pen & 13 & 20 & Post & I \\
\hline Wst* & 19 & Mid & $\mathrm{N}$ & - & Fln & 14 & 18 & Post & I \\
\hline App & 22 & Mid & $\mathrm{P}$ & 2 & $\mathrm{Neo}$ & 15 & 9 & Prime & I \\
\hline But & 22 & Mid & $\mathrm{P}$ & 2 & Ful & 16 & 19 & Post & I \\
\hline Ala & 23 & Mid & $\mathrm{N}$ & 5 & Sil & 17 & 17 & Post & I \\
\hline Bla* & 15 & Low & $\mathrm{N}$ & - & Wme & 18 & 20 & Post & I \\
\hline Fan & 15 & Low & $\mathrm{N}$ & 11 & Pig & 19 & 20 & Post & I \\
\hline Blu* & 17 & Low & $\mathrm{N}$ & - & Luc & 20 & 21 & Post & I \\
\hline Fet* & 18 & Low & $\mathrm{N}$ & 10 & Fug & 21 & 20 & Post & I \\
\hline Bon & 20 & Low & $\mathrm{N}$ & - & Ber & 22 & 21 & Post & I \\
\hline Her & 20 & Low & $\mathrm{P}$ & 2 & Tec & 23 & 20 & Post & I \\
\hline Ste* & 20 & Low & $\mathrm{P}$ & 2 & Cha & 24 & 24 & Post & I \\
\hline Duk & 23 & Low & $\mathrm{P}$ & 2 & & & & & \\
\hline Eyl & 23 & Low & $\mathrm{P}$ & - & & & & & \\
\hline Omi & 29 & Low & M & - & & & & & \\
\hline
\end{tabular}

$M$ multiparous, $P$ primiparous, $N$ nulliparous, $N$ natal, $I$ immigrant

${ }^{a}$ The females marked with an asterisk were attractive for the males and thus included in the analyses (see text for explanations)

${ }^{\mathrm{b}}$ Ordinal rank order calculated from behavioral data. Note that the rank order slightly differs from the one calculated based on the outcome of peanut tests in Bissonnette et al. 2009

${ }^{\mathrm{c}}$ Prime males, aged 7-12; post-prime males, aged $>12$ (see details in text)

${ }^{\mathrm{d}}$ The natal status was known from birth record (Affenberg Salem, unpublished data)

2001), and the contraceptive effect is achieved through a variety of mechanisms that range from anovulation to insufficient luteal phase (Croxatto 2002). So far, very few studies have been conducted on the effect of levonogestrel implants on non-human primate females, but current evidence suggests that levonogestrel implants provide effective contraception without necessarily inhibiting the expression of ovarian cycles (Pan troglodytes: Bettinger et al. 1997; Papio h. hamadryas: Plowmann et al. 2005; Pithecia pithecia: Savage et al. 2002). To date, the impact of levonogestrel implants on female ovarian activity or sexual attractivity in Barbary macaques during the mating season has not received systematic empirical attention (but see Wallner et al. 2007 for a study on levonogestrel implants in Barbary macaques outside the mating season).

In the study group, 13 implanted females and two nonimplanted females showed very low levels of sexual activity during the mating season (e.g. range of ejaculatory copulations, 0-10; median, 0, all sampling sources combined), and a lack of a strict temporal pattern of sexual activity was found in one additional female (i.e. 18 isolated ejaculatory copulations were spread over a period of 1.5 month). These 16 females were thus excluded from the analyses. Six implanted females were attractive to males and showed clear periods of mating and consorting activity, separated by periods without any sexual activity, as observed in naturally cycling females. Eleven mating 
phases (one to two per female) were identified in the six implanted females (mean length/female, 10.7 days; range, 5-24) and eight mating phases (one to three per female) in the five non-implanted females (mean length/ female, 18.9 days; range 8-28). Overall, the mating phases were shorter, but not significantly, in implanted than non-implanted females (Mann-Whitney, $n=11$, $\mathrm{U}=$ $5.5, p=0.082$ ). Most importantly for the purposes of this study, no significant difference was found in female attractivity in the mating phase between the implanted and non-implanted females (mean hourly rate of ejaculatory copulation \pm SEM, non-implanted females, $1.30 \pm$ 0.23 ; implanted females, $1.26 \pm 0.27$, Mann-Whitney, $n=$ $11, \mathrm{U}=14, p=0.86$; mean proportion of time spent in consortship, non-implanted females, $0.45 \pm 0.05$; implanted females: $0.55 \pm 0.09, n=11, \mathrm{U}=11, p=0.47$; data not shown). Thus, we assumed that the males did not differently perceive the sexual attractivity of the six implanted and five non-implanted females and we included all the 11 females in the analyses.

\section{Dominance ranks}

Dyadic aggressive acts (open-mouth threat, lunge at, chase, slap, grab, bite) and approach/retreat interactions were used to construct a dominance matrix. If an agonistic interaction turned into a polyadic interaction, only the sequence preceding the intervention of a third party was considered. The program Matman (de Vries et al. 1993) implemented in Excel was used to generate the ordinal rank order among the males. Despite the large number of males, a significantly linear hierarchy was found in the study group (Landau's linearity index corrected for unknown relationships: $0.46, P<0.0001$ ). The percentage of bidirectional relationships was $12.3 \%$, whereas $36.2 \%$ of male-male relationships remained unknown. The alpha position was occupied by the same male (Yak, aged 14 years old) since at least 2 years before the beginning of the current study (staff of the Affenberg, pers. comm.). Dominance ranks of males were strongly correlated with age, with younger adults occupying higher ranks than older adults $\left(r_{\mathrm{s}}=-0.70\right.$, $P<0.001, N=24$; Table 2). For females, only classes of dominance (high, middle, low) could be determined due to small sample size (i.e. not all females were chosen as focal individuals, see criteria above).

\section{Definitions}

Consortship: an exclusive male-female dyad in which (1) close social proximity (within $10 \mathrm{~m}$ ) and (2) grooming, prolonged body contact and/or coordinated movements when walking were observed and is restricted to mating periods (modified from Paul 1989). Only consortships lasting more than $5 \mathrm{~min}$ were included in the analyses.
A changeover in consortship typically occurred through the direct switch of a female from the ex-consorting partner to a new partner. However, changeovers were not always direct, i.e. a consortship between male A and a female could be followed by the female being in a non-consortship with male $\mathrm{B}$ (minimal criterion: male $\mathrm{B}$ was the only male within $10 \mathrm{~m}$ of the contested female) before a new consortship was formed with male C. In such cases of "indirect changeovers", we examined the pattern of behavior between male $\mathrm{B}$ and $\mathrm{C}$ because we considered that male $\mathrm{B}$ was the main rival of $\mathrm{C}$ at the time $\mathrm{C}$ established its consortship. Only confirmed successful consortship changeovers (i.e. which led to at least one ejaculatory copulation by the new male partner) were used for the analyses.

Either the new male partner or the female may be responsible for the initiation of the new consortship. The initiator of a consortship was defined as the animal that made the approach (i.e. walked to within $2 \mathrm{~m}$ of the partner) resulting in the establishment of a consortship (cf. Taub 1980, p. 293). When both animals approached each other simultaneously, the consortship was considered to have been mutually formed.

To investigate the behavioral factors responsible for the mating success of individual males, we determined the activity pursued by the new male partner in the context of changeovers in consortships. Seven behavioral categories of changeovers in consortships were defined (modified from Noë and Sluijter 1990):

1. Solo changeover: the new male partner obtained access to the female after a dyadic agonistic conflict with a rival male. The rival male was usually the previous sexual partner (i.e. direct changeover), but cases where males competed over an unattended female were also observed. An agonistic conflict is defined as any interaction between two individuals in which at least one agonistic behavioral element (threat, attack) was shown.

2. Coalitionary changeover: the new male partner obtained access to the female by forming a coalition or using the threat of coalition against the previous male partner. A coalition was defined as joint aggression between at least two males against a common target and was often preceded by signaling between the attackers (cf. Harcourt and de Waal 1992). Barbary macaques signal their intention to form a coalition mainly by performing a silent-scream face, where the mouth is wide open and the lips are completely retracted so showing the teeth (Deag 1974; Bissonnette 2009). Prolonged glances can concurrently be made at other individuals (e.g. "show-looking": de Waal et al. 1976; "head-flagging": Packer 1977). "Scream fights", which are characterized by two primary antagonists screaming at each other and third parties joining the conflict as a response, represent a separate phenomenon and were excluded from this study. The threat of coalition is defined as the use of a recruitment signal 
(see above) by the new male partner, which did not translate in the formation of a coalition but was immediately followed by the previous male partner walking away from the female.

3. Opportunistic changeover: the new male partner obtained access to a female after one or more adult males directed aggression against the previous male partner (i.e. solo aggression or coalition), but without the new male partner to be involved in the conflict himself.

In many instances the new male partner obtained access to a female in the absence of any apparent agonistic conflict between the rival males. We divided these "aggression-free" changeovers in three categories:

4. Coercive changeover: the new male partner obtained access to a female by displacing, lunging at, or chasing the female, thus herding her away from rival male(s).

5. Avoidance by the previous male partner of the new partner was scored when an ongoing association between the previous partner and a female was terminated either because the female partner walked away from its partner and directly moved near or approached a male rival or the ex-mating partner stopped following or walked away from its female partner in response to the new male partner moving toward the pair. It was important that the previous male partner was still showing interest in the female at the time of the changeover (i.e. he was grooming or following her).

7. Abandonment was scored if the ex-mating partner voluntarily moved away from the female or did not follow its female partner, but this was not due to the female partner approaching a male rival or in response to a new male partner moving toward the pair.

8. Other: Changeovers that did not easily fit to the categories described above were put together in this category.

Responsibility in the initiation of the new consortship (see definition above) was coded independently of the tactic used by the new male partner because for males winning an encounter against another male only represented the first step towards mating success (e.g. if a male obtains a consortship through solo competition, the male or the female may ultimately be responsible for initiating the consortship).

Testing the priority-of-access model

\section{Female attractive and peri-ovulatory days}

The attractive days were identified based on the time spent in consortship, as we assumed that this parameter probably represents the best indicator of males' willingness to invest time and energy in a female. This is further justified by the observation that consortships in Barbary macaque are maintained mostly by males (Heistermann et al. 2008). Thus, males almost always followed the female while in locomotion while the reverse was extremely rare (Kuester and Paul 1992; own observation).

A female's attractivity is a continuous variable that we had to dichotomize into "attractive" and "non-attractive" for each day to make it tractable. The total time spent in consortships during female focal follows ranged from 0 (not consorted) to 1 (consorted during the entire focal session). The cutoff point was arbitrarily set at 0.50 , i.e. we considered that a female which was consorted at least $50 \%$ of its focal time was attractive for the males and included as "attractive days" all female days with values equal to or higher than 0.50 . The hourly rate of ejaculatory copulation of females was higher on attractive than non-attractive days, which justifies the above decision (hourly rate of ejaculatory copulations/female \pm SEM, non-implanted females, "attractive days": $1.62 \pm 0.28$ versus "non-attractive days": $0.64 \pm 0.11$, Wilcoxon signed rank test, $n=5, z=-2.023, p=0.043$; implanted females: $1.47 \pm 0.28$ versus $0.89 \pm 0.20$, Wilcoxon signed rank test, $n=6, z=-2.02$, $p=0.043$ ).

A second, independent way to operationalize attractivity is to restrict it to peri-ovulatory days. The estimated periovulatory period was identified for each female mating cycle based on the day of attractivity breakdown (see also Chapais 1983b; Kuester and Paul 1984), as it represents a reliable indicator of the time of ovulation in this species in the absence of endocrinological data (Heistermann et al. 2008). The diagnostic behavioral criterion of the attractivity breakdown is a steep decrease (or complete cessation) of copulations, a drop in consortship activity (from $\geq 50 \%$ of female focal time to $0-30 \%$ in the current study) and male inspections of females (Kuester and Paul 1984; Heistermann et al. 2008). The "estimated peri-ovulatory period" was identified as follows: we identified a 3-day window in which ovulation was more likely (day -2 to day -4 from attractivity breakdown) and defined the "estimated peri-ovulatory period" as the period comprising these 3 days plus the three preceding days in order to account for sperm survival (Behdoodi et al. 1991; Wilcox et al. 1995) in the female's reproductive tract (i.e. day -2 to day -7 ). Note that we applied this procedure and use the term "peri-ovulatory" period for both implanted and non-implanted females, despite the possible absence of ovulation in the former. The day of attractivity breakdown could be precisely determined in 13 out of 19 "estimated peri-ovulatory periods" and was assigned in the six remaining periods with a possible margin of error of \pm 1 day. Note that the two study females who gave birth in the following year did not show postconception cycles (the approximate date of conception was calculated on the basis of a 165-day gestation length; cf. Kuester and Paul 1984). 


\section{Calculating expected mating success}

We assigned expected mating success based on the priority-ofaccess model following Altmann (1962). The expected proportion of ejaculatory copulations for each male rank over the study period was calculated as follows: the expected proportion of ejaculatory copulations by the alpha male equaled the number of days that at least one female was attractive/peri-ovulatory, divided by the total number of female attractive/peri-ovulatory days; the expected proportion by the second male equaled the number of days that at least two females were attractive, divided by the total number of female attractive/peri-ovulatory days; and so on for lowerranking males. This operationalization reflects the PoA model in that it assumes that a male is able to monopolize only one female on a given day and that he alone should be responsible for all ejaculatory copulations observed with that female on that day. The observed proportion of ejaculatory copulations for individual males equaled the number of ejaculatory copulations that a male performed with a female on a given attractive/peri-ovulatory day, divided by the total number of ejaculatory copulations performed by all males with that female on that day. These daily proportions were summed up for each male over all female attractive/peri-ovulatory days and divided by the total number of female attractive/periovulatory days to give an observed mating success per male rank over the study period. Data from all sources were combined in order to provide a more comprehensive picture of the sexual activity of females on any given day.

Kuester and Paul (1994) provided evidence for a strong mating inhibition between co-residing maternal relatives, including brother/sister dyads and uncle/niece dyads. As a consequence, the expected values for the alpha and beta males were calculated by excluding their maternal relatives as potential mates (e.g. when only one of the alpha male's maternal relative was attractive/peri-ovulatory, the beta male was expected to monopolize her).

\section{Statistics}

Logistic regression (Quinn and Keough 2002) was used to determine if females were more likely to initiate their consortships according to male age or rank. The responsibility in consortship initiation was determined as explained above (coded 1 if initiated by female and 0 if initiated by a male). Age was known from birth records and is a continuous variable. Rank was determined as explained above and is an ordinal variable (i.e. ranging from 1 to 24 ). Because individuals contributed more than one data point in the data set, we included a random effect for the male partner and the female partner. Logistic regressions were performed with the help of the program $\mathrm{R}$ v.2.6.0 (R Development Core Team 2010).
We used two different indices of mating skew (cf. Kutsukake and Nunn 2006). First, we used the "lambda" index of mating skew (Kokko and Lindström 1997). Lambda ranges from 0 (mating evenly distributed) to 1 (mating completely skewed towards one male). Second, we used the binomial skew index (hereafter B index; Nonacs $2000,2003)$. A positive value of the $B$ index indicates that skew is greater than expected, whereas negative values indicate that matings are more equally distributed than expected. An important advantage of the B index is that the observed skew can be tested against a null hypothesis of random mating within the group (indicated by $\mathrm{B}=0$ ). The lambda and $\mathrm{B}$ indices were calculated with the Skew Calculator 2003 available online at www.obee.ucla.edu/ Faculty/Nonacs (10,000 permutations). The remaining analyses were performed with the statistical package SPSS 14.0. Continuous variables used in the Pearson correlation tests were tested for normality with the Shapiro-Wilk test before performing the analyses. All remaining tests were non-parametric. The significance level alpha was set to 0.05 .

\section{Results}

Female mating synchrony

The mating season started on October 20th, when two females showed the beginning of their first mating period, and ended on February 8th with the end of the last mating period. During the mating season, attractive or peri-ovulatory females were present on $73.2 \%$ and $56.3 \%$ of the focal observation days, respectively. Up to four or five females were simultaneously attractive or peri-ovulatory, but on $45.3 \%$ of attractive days and $65.3 \%$ of "estimated peri-ovulatory days" no other female was attractive/peri-ovulatory. Thus, there were always more adult males present than there were attractive/peri-ovulatory females, i.e. the operational sex ratio was always strongly biased in favor of males. The observed mating success of males on "estimated peri-ovulatory days" and attractive days was very highly correlated (Spearman correlation, $r_{\mathrm{s}}=0.955$, $P<0.001, N=24)$.

\section{Priority-of-access model}

Complete monopolization of an attractive/peri-ovulatory female was only achieved by the dominant male with the beta female (M2d, maternally unrelated). This pair was seen together from Oct. 20th until Nov. 27th, with a 3-day interruption (26th-28th October) where the female was seen to copulate with four other males. During the monopolization period, the dominant male completely ignored the mating cycle of two other (maternally unrelated) 
females. In the remainder of the mating season, the dominant male achieved matings with other females during shorter, non-exclusive consort bouts.

Figure 1 shows the predicted proportion of ejaculatory copulations for each male of each rank, calculated using the PoA model, for all attractive days (Fig. 1a) and periovulatory days (Fig. 1b). Both graphs show that the quantitative fit of the data to the priority-of-access model is poor, with males ranked 5-24 mating more than expected. To quantify the extent of mating skew in the study group, we used the "lambda" index of mating skew. The lambda index indicates that mating skew is rather low in the study group (lambda index: attractive days, 0.15; peri-ovulatory days, 0.16 ; illustrated by the shallow shape of the observed distribution of matings in Fig. 2). When we tested the distribution of mating against a null hypothesis of random mating within the group using the $\mathrm{B}$ index, we found that the distribution of mating differs from zero and thus was significantly skewed among the males (attractive days, $0.0396 ; P=0 ; 95 \%$ confidence interval, 0.0362 0.044 ; peri-ovulatory days, $0.0435 ; P=0 ; 95 \%$ confidence interval, 0.0396-0.0545).

The presence of a correlation between male absolute rank and mating success on both attractive and peri-ovulatory days (attractive days, Spearman correlation: $r_{\mathrm{s}}=-0.74, P<0.001$,
$N=24$; peri-ovulatory days: $r_{\mathrm{s}}=-0.70, P<0.001, N=24$; rank of alpha male $=1$ ) confirm that males occupying a high rank had an advantage in mating competition, albeit much less than expected based on the PoA model. Since male age and rank were closely related in the study group with younger adults occupying higher ranks (Table 1), male age and male rank were equally good at predicting male mating success (with age: attractive days, $r_{\mathrm{s}}=-0.78, P<0.001, N=24$; peri-ovulatory days: $\left.r_{\mathrm{s}}=-0.75, P<0.001, N=24\right)$.

Behavioral mechanisms decreasing skew: the male perspective

In an attempt to determine the proximate mechanism(s) that led to the lower-than-expected mating skew based on the PoA model, we examined the tactics used by new male partners in the context of changeovers in consortships (virtually all ejaculatory copulations used in the calculations of the PoA model occurred in that context). We used male relative rank to distinguish between the consortships acquired by a dominant male from a subordinate rival and those acquired by a subordinate male from a dominant rival. The latter are of particular interest because they contributed to decreasing mating skew. The analyses were performed for access to attractive and peri-ovulatory
Fig. 1 The calculations of the PoA model are based on 321 ejaculatory copulations performed by 21 males on 79 female attractive days and 257 ejaculatory copulations performed by 21 males on 78 female peri-ovulatory days (see details in text). Proportion of ejaculatory copulations by males of each rank. Predicted values were calculated from the distribution of female a attractive days or $\mathbf{b}$ peri-ovulatory days using the PoA model

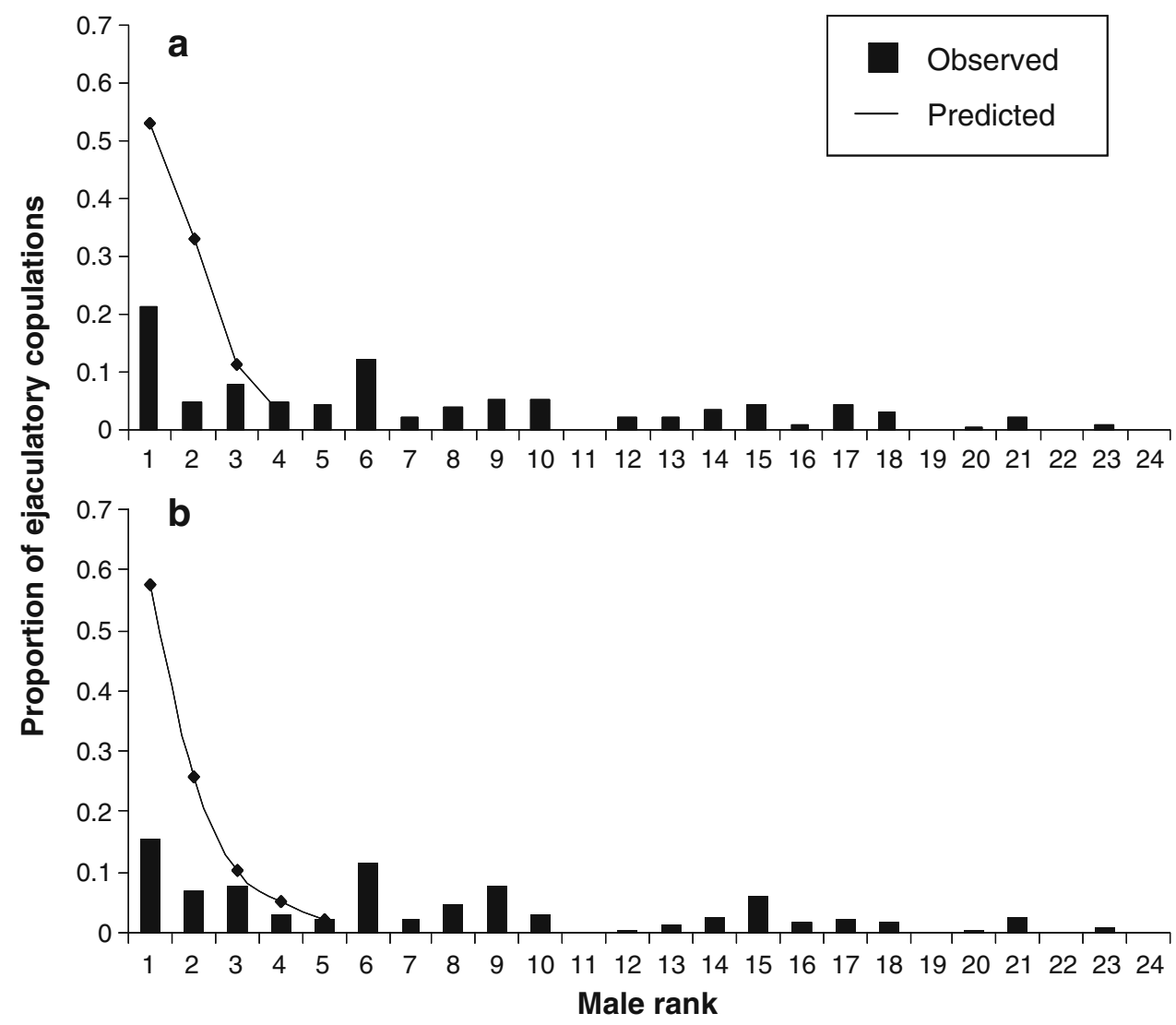




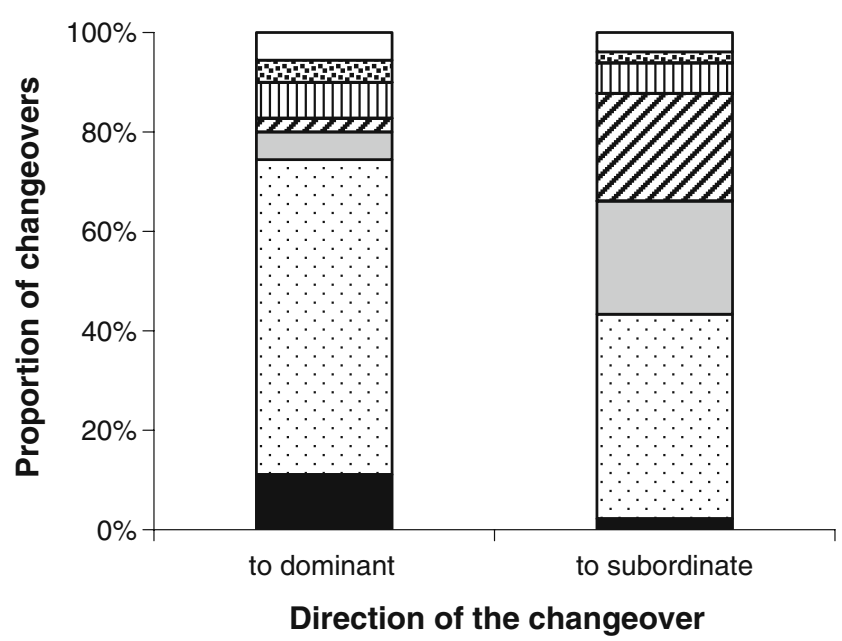

$\square$ Other $\quad$ Opportunistic $\square$ Coercive $\square$ Abandons
$\square$ Coalition $\square$ Avoidance $\square$ Solo contest

Fig. 2 Types of changeovers in consortships according to male relative rank. To dominant, the new male partner was dominant to the previous male partner; to subordinate, the new male partner was subordinate to the previous male partner $(N=193)$. A large proportion of the changeovers going to a subordinate male and classified as "avoidance" may rather belong to the category "coalition". If we accept this interpretation, it would increase the proportion of changeover related to coalitionary activity to $47 \%$ (and decrease that of avoidance to $17 \%$; see explanations in text)

females, but because very similar results were obtained for both data sets (unpublished results) we only present the analyses of 193 successful changeovers over females on their attractive days for which the tactic used by the new male partner could be identified. Figure 2 shows the frequency of male tactics that produced a changeover in consortships according to male relative dominance rank.

The majority of consortships obtained by a subordinate male from a dominant rival occurred through avoidance (34/83, i.e. $41 \%)$, coalitionary changeovers $(19 / 83$, i.e. $23 \%)$ or abandonment $(18 / 83$, i.e. $22 \%$; see Fig. 2). Coalitionary changeovers occurred when two subordinate males directed a successful coalitionary attack against a more dominant male who was consorting a female or attempting doing so (12 cases) or when the threat of such a coalition successfully led to the retreat of the dominant male (seven cases; see the operational definition in the "Methods" section). The dominant coalition partner formed a new consortship and/or mated with the contested female after most (8/12) of the successful coalitions, although the subordinate partner sometimes obtained access to the female (subordinate, three cases; both partners sequentially, one case). In all cases of coalitionary changeover, the target of the coalition was a prime male occupying a high rank ( $N=6$ males; mean age, 10 years; mean absolute rank, 7) and the coalition partners were middle- to low-ranking post-prime males ( $N=10$ males; mean age, 18 years; mean absolute rank, 14). On average, $20 \%$ of the consortships obtained by a post-prime male below rank 4 were attributed to coalitionary activity (median, 17\%).

The finding that dominant males often lost a female through avoidance of a subordinate male was unexpected (Fig. 2). A closer look at the data revealed that in almost $60 \%(20 / 34)$ of the cases a prime male avoided a subordinate male, who was a post-prime male. In all 20 cases, the new post-prime male partner had already formed a coalition against the prime male earlier in the mating season. It has already been reported that the response of Barbary macaque males to the threat of a coalitionary attack could be subtle, so that a prime male could already retreat from a female if only one post-prime male appeared (Kuester and Paul 1992). If we accept the possibility that prime males may have forgone mating opportunities in response to the potential threat of a coalitionary attack by a subordinate post-prime male, it would increase the proportion of changeover related to coalitionary activity to $47 \%$ (and decrease that of avoidance to 17\%). Of the 14 remaining cases of avoidance by a dominant individual, 13 occurred when a dominant post-prime or prime male lost his consort to a subordinate prime male, and one occurred in a dyad of post-prime males.

The frequency of the tactics used by dominant males to acquire consortships from subordinate rivals strikingly differed from the picture presented above. The vast majority of the cases $(70 / 110$, i.e. $64 \%)$ occurred though avoidance by the subordinate rival. Only ten instances of overt aggression and two cases of escalation to a fight were observed (Fig. 2). The majority of the consortships by the four top-ranking males were obtained through avoidance $(20 / 43,47 \%)$ and solo contest $(7 / 43,16 \%)$.

\section{Behavioral mechanisms decreasing skew: the female} perspective

Females in our study showed a promiscuous mating pattern: attractive and peri-ovulatory females were involved in ejaculatory copulations with one to 13 males per cycle (mean attractive female, 7.3; mean peri-ovulatory female, 5.4). To determine to what extent females actively sought out multiple males, we looked at how often females were responsible for initiating their consortships and how they distributed their initiations over males of different dominance rank or age. The analyses were performed for females on their attractive and peri-ovulatory days, but because very similar results were obtained for both data sets (unpublished results) we only present the analyses of 225 changeovers with attractive females for which the initiator of the new consortship could be identified (mean number of consortship per female, 20.6; range, 3-63). Our data show 
that females and males initiated similar proportions of consortships (females, 121; males, 102; both, 2), with individual females establishing on average $43.3 \%$ (range $0-83.3 \%$ ) of their consortships themselves. On average, during observation times, attractive females initiated consortships with 5.1 (range 1-11) different partners.

Logistic regression revealed that females were more likely to initiate consortships with prime than post-prime males but did so independently of male rank (Table 3). Of all female-initiated consortships, $69.4 \%(84 / 121)$ was directed towards prime males and in $69 \%(58 / 84)$ of those cases the females visited them up in a tree where prime males were isolated, likely as a result of coalitionary activity (Bissonnette 2009). In other words, prime males heavily depended on females to acquire their consortships (84/105 female-initiated), whereas post-prime males were most often the initiators (37/118 female-initiated; chi-square goodness-of-fit, $\chi^{2}=7.09(1), P=0.008$; Fig. 3). Because females preferentially initiated their consortships with prime males, who generally (but not always) occupied a higher rank than the previous male partner, females were also more likely to initiate consortships with a new dominant partner (new partner is: dominant, $58.2 \%$; subordinate: $34.1 \%$; chi-square goodness-of-fit: $\chi^{2}=7.09$ (1), $P=0.008$ ). On average, $85 \%$ of the consortships obtained by a prime male below rank 4 were initiated by females (median, 85\%), which suggests that both female behavior and male coalitionary activity are involved in the deviations from expectations based on the PoA model.

\section{Discussion}

Our data confirm the findings of a number of authors that a low to medium skew is a constant characteristic of Barbary macaque males (cf. Table 1; one exception in a small group with one to two adult males; Witt et al. 1981). By providing a first test of the PoA model in this species, we could show that female mating synchrony sets an upper limit to the monopolization potential of dominant males, as would be expected in a seasonally breeding species (Cowlishaw and Dunbar 1991; Paul 1997), although this factor alone was not sufficient to explain the distribution of matings among male ranks (see below). The artificial change in the number of attractive females due to the birth control policy is likely to have influenced the course of the mating season by artificially decreasing female mating synchrony. If all females would have displayed normal levels of sexual activity, female mating synchrony would have been higher, resulting in lower monopolization potential for high-rankers (i.e. the slope of the expected regression curve of mating success on rank would have been shallower). However, unless the majority of the females had been receptive simultaneously (i.e. pure scramble situation), we would have expected mid- to low-ranking post-prime males to have used coalitions against higher-ranking prime males as a way to increase their mating success (Pandit and van Schaik 2003) as observed in the study of Kuester and Paul (1992) before the instauration of the birth control policy in Salem, thus leading to an imperfect fit to the expectations based on the PoA model.

Our results suggest that there are some benefits associated with a high rank for a Barbary macaque male, although relatively low in comparison to other nonseasonally breeding species (e.g. chacma baboons: Weingrill et al. 2003; long-tailed macaques: Engelhardt et al. 2006; mandrills: Setchell et al. 2005). Barbary macaques, like other primate species (Alberts et al. 2003; Rodriguez-Llanes et al. 2009), appear to show intraspecific variation in the association between male dominance rank and estimates of mating or reproductive success (cf. Table 1), but the reasons for this variance are poorly understood. Current evidence suggest that the presence of a stable dominance hierarchy is a prerequisite to an association between rank and mating success in this species (e.g. Paul 1989; but see Brauch et al. 2008) and similar primates (e.g. Bulger 1993), but the degree to which a high rank may confer benefits to males may appear to be at least partly contingent upon the frequency and efficiency of male coalitions and female mating behavior.
Table 3 Independent variables predicting the likelihood of females' responsibility in initiating consortships in a logistic regression analysis $(N=223$ consortships)

\begin{tabular}{lcccc}
\hline Independent variable & Regression coefficient & SE & $z$ & $P$ \\
\hline Univariate analyses & & & & \\
Male age & -0.2 & 0.04 & -4.45 & $<0.0001$ \\
Male rank & -0.07 & 0.05 & -1.46 & 0.143 \\
Multivariate analyses & & & & \\
Male age & -0.27 & 0.11 & -2.42 & 0.015 \\
Male rank & -0.05 & 0.14 & -0.34 & 0.734 \\
Male age×male rank & 0.01 & 0.01 & 0.53 & 0.593 \\
\hline
\end{tabular}




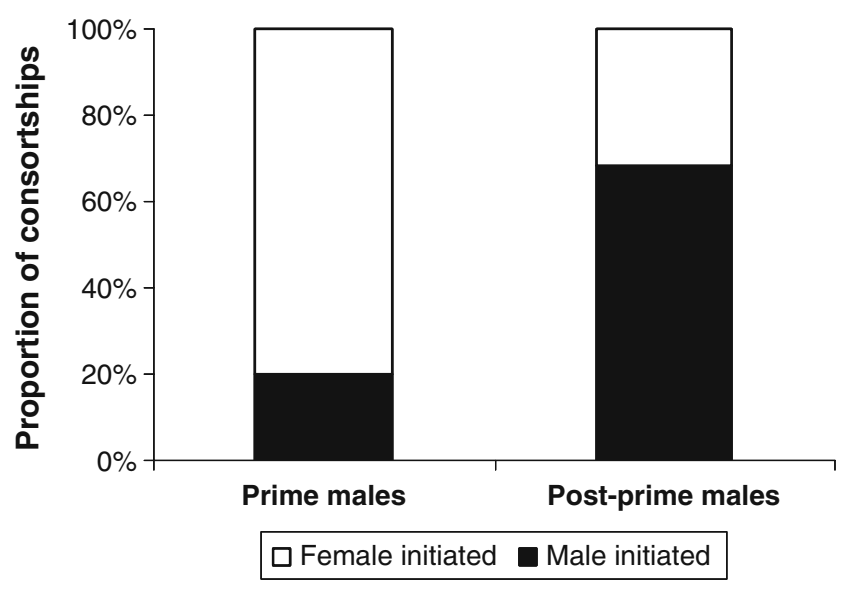

Fig. 3 Proportion of consortships initiated by males and females according to male age class $(N=105$ consortships with prime males and $N=118$ consortships with post-prime males; two consortships that were initiated by both partners are not shown)

\section{Coalition formation and female mating behavior}

In the current study, mostly mid- to low-ranking post-prime males used the coalitionary tactic to level mating access by targeting a higher-ranking male who was consorting a female or preventing a higher-ranking target from establishing a consortship at all. The success rate of coalitions in producing a consort changeover was $42.1 \%$, which lies within the range reported for male baboons (i.e. between $30 \%$ and 65\%, Bercovitch 1988; Noë 1992, Table 11.1). Unsuccessful changeovers sometimes occurred when the coalition was behaviourally unsuccessful (i.e. did not defeat the target, cf. Bissonnette et al. 2009) or when a coalition was behaviourally successful but did not translate into mating access for the coalition partners because the female initiated a consortship with a third party not involved in the conflict or re-established the previous consortship with the target of the coalition. Overall, all-up, leveling coalitions accounted for an important proportion (23\%) of changeovers from a dominant male to a subordinate challenger and thus played an important role in decreasing mating skew. However, we think that this figure may only represent a conservative estimate of the impact of coalitionary activity on mating skew. Indeed, if we accept the possibility that prime males sometimes forwent mating opportunities by avoiding subordinate, post-prime males who formed coalitions against them in the past, as suggested by others (Kuester and Paul 1992), the proportion of changeovers related to coalitionary activity reaches $47 \%$. The reasons underlying this strong age-related pattern in coalition formation are currently under investigation.

In this paper, we only reported figures from coalitions over direct access to females. However, coalitions in this context (successful and unsuccessful ones) represented only one third of all coalitions observed during the mating season (Bissonnette 2009), and this figure is comparable to what is observed in savannah baboons (Noë 1990, 1992). Elsewhere (Bissonnette 2009), we have presented empirical evidence suggesting that coalition formation in Barbary macaques has an additional function, namely, to drive away prime males during the mating season, resulting in them being isolated in trees and refraining from competition during the day, as originally suggested by Kuester and Paul (1992). This leaves an important outstanding question: given that prime males were the frequent target of coalitions, why did they nevertheless secure a share of the matings in the study group? The most likely answer is that prime males heavily relied on females to achieve matings (Fig. 4). Indeed, while females mated promiscuously with several males during a given mating cycle, they were more likely to initiate their consortships with prime males by visiting them in the trees. Although age and rank are closely and inversely related in the study group (in other Barbary macaque studies: Paul 1989; Brauch et al. 2008; in other macaque species: van Noordwijk and van Schaik 2004; Rodriguez-Llanes et al. 2009), the results of logistic regression indicated a strong effect of male age independent of rank on the initiation of consortships by females. Thus, irrespective of their underlying strategy, females apparently impeded post-prime males to accumulate a disproportionate share of the matings. This study provides another clear example of how the observed skew among males can be a compromise between male and female mating efforts (e.g. Manson 1992; Soltis et al. 1997).

Most Barbary macaque studies conducted so far concluded that a lack of female partner preference is characteristic of this species (Kuester and Paul 1992; Small 1990; Taub 1980), although Brauch et al. (2008) recently reported evidence of female direct mate choice for higherrankers during fertile periods. We think that female mate

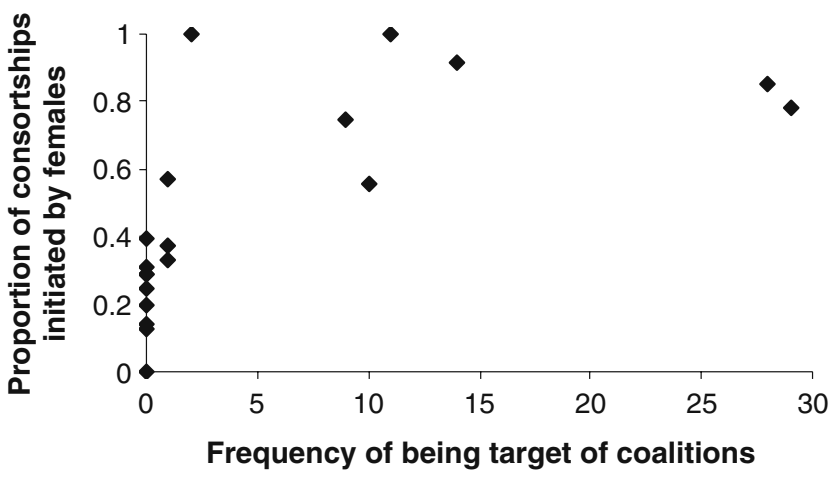

Fig. 4 Females initiated more consortships with (prime) males who also were the most frequent target of coalitions in the study group $\left(r_{\mathrm{s}}\right.$ : $-0.858, p=0.002, N=19$ ). Five males who never formed consortships or consorted only once are now shown. Male coalitionary data from Bissonnette (2009) 
choice for prime males in the current study may reflect the unusually large number of post-prime males, which enabled the post-prime cohort to effectively peripheralize the prime males during the mating season. As a consequence, females may have used different tactics to achieve copulations with males of different age class, i.e. they may have actively approached prime males as a part of a promiscuous strategy which aims at equalizing matings among males (for a similar argument in rhesus macaques, see Manson 1992). Among the potential benefits of promiscuous mating for Barbary macaque females would be avoiding inbreeding or genetic incompatibilities (e.g. Zeh and Zeh 2001), allowing sperm from various males the chance to compete for fertilization (e.g. Dixson 1998; Brauch et al. 2008) and reducing the risk of infanticide (e.g. Hrdy 1979; van Schaik et al. 2004), as proposed in many other primate species (e.g. Hrdy 2000; Paul 2002; Nikitopoulos et al. 2005). However, we cannot exclude the possibility that Barbary macaque females show intra-specific variation in that respect and that females in the current study showed a real preference for prime males, although this pattern does not appear to be common in primates (Small 1990; Paul 2002; Soltis 2004). To fully understand this issue, an experimental setup would be needed where females have complete control over access to males of different age and rank (see Nikitopoulos et al. 2005 for an example in long-tailed macaques). This approach was outside the scope of this study.

\section{Limited control or concession?}

What can our data tell us about which model of reproductive skew best fit Barbary macaques? The observations in the study group that female mating cycles overlap to a certain extent and that male-male coalitions and female behavior can influence mating skew provide convincing support for the limited control model. Interestingly, although the alpha male (who was past his prime) has never been observed to be the target of coalitionary attacks, he nevertheless did not get the lion's share of the matings. We found no evidence suggesting that his natal status had a negative impact on his mating success, as he achieved at least one ejaculatory copulation with most (maternally unrelated) females on their attractive days. A more likely explanation might be that the continuous presence of attractive/peri-ovulatory females, which is common in Barbary macaque groups (Kuester and Paul 1984; Small 1990; this study), have reduced the monopolization potential of the alpha male because consorting is costly in terms of time, energy, and opportunity costs (Kutsukake and Nunn 2008; Ostner et al. 2008). For example, the observation that the alpha male in our study group completely monopolized the beta female during 36 days at the beginning of the mating season, but did not show other monopolization cycles afterwards despite its ability to do so, may suggest that consorting females involve costs and thus limit the number of days a male is able to consort. However, day-long consortships appear to be uncommon in this species (reviewed in Fooden 2007), and further studies will be needed to identify the exact nature of the costs of mate guarding (if any) in Barbary macaque males.

In conclusion, it appears more likely that like other primates (Kutsukake and Nunn 2009; Ostner et al. 2008) high-ranking Barbary macaque males have a limited control over mating and thus reproduction (see also Brauch et al. 2008). On the one hand, our findings show that the ability of high-ranking males to monopolize females is limited by female mating synchrony, in line with the PoA model. On the other hand, strong deviations from the predictions of the PoA model suggest that, in addition to female synchrony, male-male coalitions and female behavior can effectively affect mating skew, sometimes in intricate ways. The study group had unusual demographic features, such as a large number of post-prime males. The relative importance of coalition formation in producing deviations from the PoA model appears to be contingent upon the cohort of postprime males (Bissonnette 2009), as suggested in savanna baboons (Alberts et al. 2003). Clearly, comparisons of groups of different age composition are needed for a better understanding of the factors influencing male mating success in Barbary macaque males.

Acknowledgments We are grateful to Walter Angst, Gilbert de Turckheim, and Ellen Merz for permission to work at the Affenberg Salem and to Roland Hilgartner and the staff of the Affenberg who provided cooperation and assistance. We also thank Bernard Chapais, Ronald Noë, and Maria van Noordwijk and three anonymous reviewers for suggesting improvements in the manuscript. The study was conducted completely noninvasively and under the authority responsible for any research on the Salem macaques. This project was supported by grants to A.B. from the Fonds de recherche sur la société et la culture of the province of Québec and from the A.H. Schultz Foundation of the University of Zürich. The authors declare that they have no conflict of interest.

\section{References}

Alberts SC, Watts HE, Altmann J (2003) Queuing and queue-jumping: long-term patterns of reproductive skew in male savannah baboons, Papio cynocephalus. Anim Behav 65:821-840

Altmann SA (1962) A field study of sociobiology of rhesus monkeys, Macaca mulatta. Ann NY Acad Sci 102:338-435

Altmann J (1974) Observational study of behavior-sampling methods. Behaviour 49:227-267

Altmann J, Alberts SC, Haines SA, Dubach J, Muruthi P, Coote T, Geffen E, Cheesman DJ, Mututua RS, Saiyalel SN, Wayne RK, Lacy RC, Bruford MW (1996) Behavior predicts genetic structure in a wild primate group. Proc Natl Acad Sci USA 93:5797-5801

Behboodi E, Katz DF, Samuels SJ, Tell L, Hendrickx AG, Lasley BL (1991) The use of a urinary estrone conjugate assay for detection 
of optimal mating time in the cynomolgus macaque (Macaca fascicularis). J Med Primatol 20:229-234

Bercovitch FB (1988) Coalitions, cooperation and reproductive tactics among adult male baboons. Anim Behav 36:1198-1209

Bettinger T, Cougar D, Lee DR, Lasley BL, Wallis J (1997) Ovarian hormone concentrations and genital swelling patterns in female chimpanzees with Norplant implants. Zoo Biol 16 (3):209-223

Bissonnette A (2009) Testing a model on coalitions in Barbary macaque males (Macaca sylvanus): $\mathrm{PhD}$ thesis, University of Zuerich, $101 \mathrm{p}$

Bissonnette A, de Vries H, van Schaik CP (2009) Coalitions in Barbary macaque males, Macaca sylvanus: success, strength and rules of thumb. Anim Behav 78(2):329-335

Boesch C, Kohou G, Nene H, Vigilant L (2006) Male competition and paternity in wild chimpanzees of the Tai forest. Am J Phys Anthropol 130:103-115

Brauch K, Hodges K, Engelhardt A, Fuhrmann K, Shaw E, Heistermann M (2008) Sex-specific reproductive behaviours and paternity in free-ranging Barbary macaques (Macaca sylvanus). Behav Ecol Sociobiol 62:1453-1466

Bulger JB (1993) Dominance rank and access to estrous females in male savanna baboons. Behaviour 127:67-103

Cant MA (1998) A model for the evolution of reproductive skew without reproductive suppression. Anim Behav 55:163-169

Chapais B (1983a) Mate selection among the Cayo Santiago rhesus monkeys. Am J Primatol 4:328-329

Chapais B (1983b) Reproductive activity in relation to male dominance and the likelihood of ovulation in rhesus monkeys. Behav Ecol Sociobiol 12:215-228

Charpentier M, Peignot P, Hossaert-McKey M, Gimenez O, Setchell JM, Wickings EJ (2005) Constraints on control: factors influencing reproductive success in male mandrills (Mandrillus sphinx). Behav Ecol 16:614-623

Clutton-Brock TH (1998) Reproductive skew, concessions and limited control. Trends Ecol Evol 13:288-292

Clutton-Brock TH, Brotherton PNM, Russell AF, O'Riain MJ, Gaynor D, Kansky R, Griffin A, Manser M, Sharpe L, McIlrath GM, Small T, Moss A, Monfort S (2001) Cooperation, control, and concession in meerkat groups. Science 291:478-481

Cowlishaw G, Dunbar RIM (1991) Dominance rank and mating success in male primates. Anim Behav 41:1045-1056

Croxatto HB (2002) Mechanisms that explain the contraceptive action of progestin implants for women. Contraception $65: 21-27$

de Turckheim G, Merz E (1984) Breeding Barbary macaques in outdoor open enclosures. In: Fa JE (ed) The Barbary macaque: a case study in conservation. Plenum, New York, pp 241-261

de Vries H, Netto WJ, Hanegraaf PLH (1993) Matman: a program for the analysis of sociometric matrices and behavioral transition matrices. Behaviour 125:157-175

de Waal F, van Hooff J, Netto WJ (1976) An ethological analysis of types of agonistic interaction in a captive group of Java monkeys (Macaca fascicularis). Primates 17:257-290

Deag JM (1974) A study of the social behaviour and ecology of the wild Barbary macaque, Macaca sylvanus L. Ph.D., University of Bristol, pp 487

Dixson AF (1998) Primate sexuality. Oxford University Press, Oxford

Ellis L (1995) Dominance and reproductive success among nonhuman animals: a cross-species comparison. Ethol Sociobiol $16: 257-333$

Engelhardt A, Heistermann M, Hodges JK, Nurnberg P, Niemitz C (2006) Determinants of male reproductive success in wild longtailed macaques (Macaca fascicularis) - male monopolisation, female mate choice or post-copulatory mechanisms? Behav Ecol Sociobiol 59:740-752

Fooden J (2007) Systematic review of the Barbary macaque, Macaca sylvanus (Linnaeus, 1758). Fieldiana: Zool 113:1-58

Glasier A (2002) Implantable contraceptives for women: effectiveness, discontinuation rates, return of fertility, and outcome of pregnancies. Contraception 65:29-37

Harcourt AH, de Waal FBM (1992) Coalitions and alliances in humans and other animals. Oxford University Press, Oxford

Hausfater G (1975) Dominance and reproduction in baboons (Papio cynocephalus): quantitative analysis. Contrib Primatol 7:2-150

Hayakawa S (2007) Female defensibility in small troops of Japanese macaques vis-a-vis nontroop males and copulation on the periphery of the troop. Int J Primatol 28:73-96

Heistermann M, Brauch K, Möhle U, Pfefferle D, Dittami J, Hodges K (2008) Female ovarian cycle phase affects the timing of male sexual activity in free-ranging Barbary macaques (Macaca sylvanus) of Gibraltar. Am J Primatol $70: 44-53$

Hrdy SB (1979) Infanticide among animals: a review, classification, and examination of the implications for the reproductive strategies of females. Ethol Sociobiol 1:13-40

Hrdy SB (2000) The optimal number of fathers. Evolution, demography, and history in the shaping of female mate preferences. Ann NY Acad Sci 907:75-96

Johnstone RA (2000) Models of reproductive skew: a review and synthesis (invited article). Ethology 106:5-26

Keller L, Reeve HK (1994) Partitioning of reproduction in animal societies. Trends Ecol Evol 9:98-102

Kokko H, Linstrom J (1997) Measuring the mating skew. Am Nat 149:794-799

Kuester J, Paul A (1984) Female reproductive characteristics in semifree ranging Barbary macaques (Macaca sylvanus L. 1758). Folia Primatol 43:69-83

Kuester J, Paul A (1989) Reproductive strategies of subadult Barbary macaque males at Affenberg Salem. In: Rasa AEC, Vogel C, Voland E (eds) The sociobiology of sexual and reproductive strategies. Routledge, Chapman and Hall, New York, pp 93-109

Kuester J, Paul A (1992) Influence of male competition and female mate choice on male mating success in Barbary macaques (Macaca sylvanus). Behaviour 120:192-217

Kuester J, Paul A (1994) Kinship, familiarity and mating avoidance in Barbary macaques, Macaca sylvanus. Anim Behav 48:1183-1194

Kuester J, Paul A (1996) Female-female competition and male mate choice in Barbary macaques (Macaca sylvanus). Behaviour 133:763-790

Kummerli R, Martin RD (2005) Male and female reproductive success in Macaca sylvanus in Gibraltar: no evidence for rank dependence. Int J Primatol 26:1229-1249

Kutsukake N, Nunn CL (2006) Comparative tests of reproductive skew in male primates: the roles of demographic factors and incomplete control. Behav Ecol Sociobiol 60:695-706

Kutsukake N, Nunn CL (2008) The causes and consequences of reproductive skew in male primates. In: Hager R, Jones C (eds) Reproductive skew in vertebrates. Proximate and ultimate causes. Cambridge University Press, Cambridge

Kutsukake N, Nunn CL (2009) The causes and consequences of reproductive skew in male primates. In: Hager R, Jones C (eds) Reproductive skew in vertebrates. Proximate and ultimate causes. Cambridge University Press, Cambridge

Magrath RD, Heinsohn RG (2000) Reproductive skew in birds: models, problems and prospects. J Avian Biol 31:247-258

Manson JH (1992) Measuring female choice in Cayo Santiago rhesus macaques. Anim Behav 44:405-416 
Martin P, Bateson P (2000) Measuring behaviour. An introductory guide, 2nd edn. Cambridge University Press, Cambridge

Menard N, von Segesser F, Scheffrahn W, Pastorini J, Vallet D, Gaci B, Martin RD, Gautier-Hion A (2001) Is male-infant caretaking related to paternity and/or mating activities in wild Barbary macaques (Macaca sylvanus)? Comptes Rendus De L Academie Des Sciences Serie Iii-Sciences De La Vie-Life Sciences 324:601-610

Modolo L, Martin RD (2008) Reproductive success in relation to dominance rank in the absence of prime-age males in Barbary macaques. Am J Primatol 70:26-34

Nikitopoulos E, Heistermann M, De Vries H, Van Hooff J, Sterck EHM (2005) A pair choice test to identify female mating pattern relative to ovulation in longtailed macaques, Macaca fascicularis. Anim Behav 70:1283-1296

Noë R (1990) A veto game played by baboons: a challenge to the use of the Prisoner's Dilemma as a paradigm for reciprocity and cooperation. Anim Behav 39:78-90

Noë R (1992) Alliance formation among male baboons: shopping for profitable partners. In: Harcourt AH, de Waal FBM (eds) Coalitions and alliances in humans and other animals. Oxford University Press, New York, pp 233-257

Noë R, Sluijter AA (1990) Reproductive tactics of male savanna baboons. Behaviour 113:117-170

Nonacs P (2000) Measuring and using skew in the study of social behavior and evolution. Am Nat 156:577-589

Nonacs P (2003) Measuring the reliability of skew indices: is there one best index? Anim Behav 65:615-627

Ostner J, Nunn CL, Schulke O (2008) Female reproductive synchrony predicts skewed paternity across primates. Behav Ecol 19:1150-1158

Packer C (1977) Reciprocal altruism in Papio anubis. Nature 265:441-443

Pandit SA, van Schaik CP (2003) A model for leveling coalitions among primate males: toward a theory of egalitarianism. Behav Ecol Sociobiol 55:161-168

Paul A (1989) Determinants of male mating success in a large group of Barbary macaques (Macaca sylvanus) at Affenberg Salem. Primates 30:461-476

Paul A (1997) Breeding seasonality affects the association between dominance and reproductive success in non-human male primates. Folia Primatol 68:344-349

Paul A (2002) Sexual selection and mate choice. Int J Primatol 23:877-904

Paul A, Kuester J, Timme A, Arnemann J (1993) The association between rank, mating effort, and reproductive success in male Barbary macaques (Macaca sylvanus). Primates 34:491-502

Pereira ME, Weiss ML (1991) Female mate choice, male migration, and the threat of infanticide in ringtailed lemurs. Behav Ecol Sociobiol 28:141-152

Plowman AB, Jordan NR, Anderson JR, Condon E, Fraser O (2005) Welfare implications of captive primate population management: behavioural and psycho-social effects of female-based contraception, oestrus and male removal in hamadryas baboons (Papio hamadryas). Appl Anim Behav Sci 90(2):155-165

Quinn GP, Keough MJ (2002) Experimental design and data analysis for biologists. Cambridge University Press, Cambridge

R Development Core Team (2010) R: A language and environment for statistical computing. In: Computing RFfS, editor, Austria

Reeve HK, Emlen ST, Keller L (1998) Reproductive sharing in animal societies: reproductive incentives or incomplete control by dominant breeders? Behav Ecol 9:267-278

Reeve HK, Keller L (2001) Tests of reproductive-skew models in social insects. Annu Rev Entomol 46:347-385

Rodriguez-Llanes JM, Verbeke G, Finlayson C (2009) Reproductive benefits of high social status in male macaques (Macaca). Anim Behav 78:643-649
Savage A, Zirofsky DS, Shideler SE, Smith TE, Lasley BL (2002) Use of levonogestrel as an effective means of contraception in the white-faced saki (Pithecia pithecia). Zoo Biol 21(1):49-57

Setchell JM (2008) Alternative reproductive tactics in primates. In: Oliveira RF, Taborsky M, Brockmann HJ (eds) Alternative reproductive tactics: an integrative approach. Cambrige University Press, Cambridge

Setchell JM, Charpentier M, Wickings EJ (2005) Mate guarding and paternity in mandrills: factors influencing alpha male monopoly. Anim Behav 70:1105-1120

Sivin I, Lahteenmaki P, Mishell DR, Alvarez F, Diaz S, Ranta S, Grozinger C, Lacarra M, Brache V, Pavez M, Nash H, Stern J (1997) First week drug concentrations in women with levonorgestrel rod or Norplant (R) capsule implants. Contraception 56:317-321

Sivin I, Wan L, Ranta S, Alvarez F, Brache V, Mishell DR, Darney P, Biswas A, Diaz S, Kiriwat O, Anant MP, Klaisle C, Pavez M, Schechter J (2001) Levonorgestrel concentrations during 7 years of continuous use of Jadelle contraceptive implants. Contraception 64:43-49

Small MF (1990) Promiscuity in Barbary macaques (Macaca sylvanus). Am J Primatol 20:267-282

Smuts B (1987) Sexual competition and mate choice. In: Smuts B, Cheney DL, Seyfarth RM, Wrangham R, Struhsaker TT (eds) Primate societies. The University of Chicago Press, Chicago, pp 385-399

Soltis J (2004) Mating systems. In: Thierry B, Singh M, Kaumanns W (eds) Macaque societies: a model for the study of social organization. Cambridge University Press, New York, pp 135-151

Soltis J, Mitsunaga F, Shimizu K, Yanagihara Y, Nozaki M (1997) Sexual selection in Japanese macaques. 1. Female mate choice or male sexual coercion? Anim Behav 54:725-736

Soltis J, Thomsen R, Takenaka O (2001) The interaction of male and female reproductive strategies and paternity in wild Japanese macaques, Macaca fuscata. Anim Behav 62:485-494

Stumpf RM, Boesch C (2005) Does promiscuous mating preclude female choice? Female sexual strategies in chimpanzees (Pan troglodytes verus) of the Tai National Park, Cote d'Ivoire. Behav Ecol Sociobiol 57:511-524

Stumpf RM, Boesch C (2006) The efficacy of female choice in chimpanzees of the Tai Forest, Cote d'Ivoire. Behav Ecol Sociobiol 60:749-765

Taub D (1980) Female choice and mating strategies among wild Barbary macaques (Macaca sylvanus L.). The macaques: Studies in ecology, behavior and evolution. New York: Van Nostrand Reinhold Co. pp 287-344

Thierry B (2007) The macaques: a double-layered social organization. In: Campbell C, Fuentes A, MacKinnon KC, Panger M, Bearder S (Eds) Primates in perspective, 2nd edn. Oxford University Press, Oxford

van Noordwijk MA, van Schaik CP (2004) Sexual selection and the careers of primate males: paternity concentration, dominance-acquisition tactics and transfer decisions. In: Kappeler PM, van Schaik CP (eds) Sexual selection in primates: new and comparative perspectives. Cambridge University Press, Cambridge, pp 208-229

van Schaik CP, Pradhan GR, van Noordwijk MA (2004) Mating conflict in primates: infanticide, sexual harassment and female sexuality. In: Kappeler PM, van Schaik CP (eds) Sexual selection in primates: new and comparative perspectives. Cambridge University Press, Cambridge, pp 131-150

Wallner B, Mostl E, Dittami J (2007) Chronic levonorgestrel treatment in Macaca sylvanus: effects on perineal swelling size and fecal sex steroid excretion. Neuroendocrinol Lett 28:326-332

Weingrill T, Lycett JE, Barrett L, Hill RA, Henzi SP (2003) Male consortship behaviour in chacma baboons: the role of demographic factors and female conceptive probabilities. Behaviour 140:405-427 
Widdig A, Bercovitch FB, Streich WJ, Sauermann U, Nurnberg P, Krawczak M (2004) A longitudinal analysis of reproductive skew in male rhesus macaques. Proc R Soc Lond Ser B-Biol Sci 271 (1541):819-826

Wilcox AJ, Weinberg CR, Baird DD (1995) Timing of sexual intercourse in relation to ovulation. N Engl J Med 333:1517-1522

Witt R, Schmidt C, Schmitt J (1981) Social rank and darwinian fitness in a multi-male group of Barbary macaques (Macaca sylvana
Linnaeus, 1758). Dominance reversals and male reproductive success. Folia Primatol 36:201-211

Wroblewski EE, Murray CM, Keele BF, Schumacher-Stankey JC, Hahn BH, Pusey AE (2009) Male dominance rank and reproductive success in chimpanzees, Pan troglodytes schweinfurthii. Anim Behav 77:873-885

Zeh JA, Zeh DW (2001) Reproductive mode and the genetic benefits of polyandry. Anim Behav 61:1051-1063 